\title{
NUMERICAL INVESTIGATION OF MICROCHANNEL HEAT SINK WITH MEPCM SUSPENSION WITH DIFFERENT TYPES OF PCM
}

\author{
Mushtaq Ismael HASAN*, \\ Mechanical Engineering Department, College of Engineering, Thi-Qar University \\ mushtaq76h@gmail.com
}

Hind Lafta TBENA, Mechanical Engineering Department, College of Engineering, Thi-Qar University hindlafta88@gmail.com

Received on 11 January 2018 Accepted on 8 April 2018 Published on 14 May 2018

DOI: 10.30772/qjes.v11i1.524

\begin{abstract}
The aim of this paper is to study the microencapsulated phase change materials (MEPCM) suspension as a coolant instead of pure fluid in the micro channel heat sink (MCHS) with different core and wall materials as well as different base fluids. The MEPCM suspension using in this study consist of microcapsules constructed from n-octadecane, RT44 as a phase change materials (PCM) and shell materials are poly-methylmthacrylate (PMMA), poly-alpha olefin (PAO), these capsules are suspended in (pure water, ethylene glycol and pure oil) in a concentration of (0-20)\% and have been used as a cooling mediums at different ambient temperatures. Constant heat flux is applied at base of heat sink. The results obtain show that, using MEPCM suspensions as a coolant in micro heat sink instead of conventional cooling with pure fluid lead to enhance the cooling performance of micro heat sink is be $20.91 \%$ with (RT44+PMMA) pure oil, $16.91 \%$ with (RT44+PMMA) for ethyleneglycol and $12.91 \%$ with (RT44+PMMA) for pure water at concentration $2 \%$ and $V_{i}=0.28 \mathrm{~m} / \mathrm{s}$. The phase change material in MEPCM suspension should be select according to its melting temperature corresponding to the certain application since different MEPCM suspension concentration caused different values of reduction in heat sink temperature in range of ambient temperature due to different in its melting temperatures.
\end{abstract}

Keywords: Micro-channel heat sink, Heat sinks, microencapsulated phase change materials, MEPCM suspension, Phase change materials 


\section{Nomenclature:}

\begin{tabular}{|c|c|c|c|c|c|}
\hline Symbol & Description & SI Unit & Symbol & Description & SI Unit \\
\hline$A$ & Cross-sectional area & $m^{2}$ & $\mathrm{u}$ & $\begin{array}{l}\text { Fluid } x \text {-component } \\
\text { velocity }\end{array}$ & $\mathrm{m} / \mathrm{s}$ \\
\hline C & Volume fraction & $\%$ & $\mathrm{v}$ & $\begin{array}{l}\text { Fluid y-component } \\
\text { velocity }\end{array}$ & $\mathrm{m} / \mathrm{s}$ \\
\hline$C p$ & Specific heat capacity & $(\mathrm{J} / \mathrm{kg} \mathrm{K})$ & w & $\begin{array}{l}\text { Fluid z-component } \\
\text { velocity }\end{array}$ & $\mathrm{m} / \mathrm{s}$ \\
\hline $\mathrm{H}$ & Channel height & $\mathrm{m}$ & $W c H$ & Channel width & $\mathrm{m}$ \\
\hline $\mathrm{h}$ & $\begin{array}{l}\text { heat transfer } \\
\text { coefficient }\end{array}$ & $\begin{array}{l}\mathrm{W} / \mathrm{m}^{2} . \\
\mathrm{K}\end{array}$ & $\mathrm{x}$ & Axial coordinate & $\mathrm{m}$ \\
\hline$\Delta \mathrm{H}$ & Latent heat & W & $\mathrm{y}$ & Vertical coordinate & $\mathrm{m}$ \\
\hline $\mathrm{He}$ & $\begin{array}{l}\text { Enthalpy of } \\
\text { suspension }\end{array}$ & W & $z$ & Horizontal coordinate & $\mathrm{m}$ \\
\hline SH & Sensible heat & W & $\rho$ & Density & $\mathrm{kg} / \mathrm{m}^{3}$ \\
\hline $\mathrm{k}$ & Thermal conductivity & $\mathrm{W} / \mathrm{m} \mathrm{K}$ & $\mu$ & Dynamic viscosity & $\mathrm{m}^{2} / \mathrm{s}$ \\
\hline$L$ & Length & $\mathrm{m}$ & $\varphi$ & Mass fraction & \\
\hline $\mathrm{m}$ & Mass flow rate & $\mathrm{kg} / \mathrm{s}$ & $\beta$ & Melting fraction & \\
\hline$\Delta \mathrm{P}$ & Pressure drop & $\mathrm{Pa}$ & \multicolumn{3}{|c|}{ Abbreviation } \\
\hline$m$ & flow rate & $\mathrm{m}^{3} / \mathrm{s}$ & $\mathrm{v}$ & volume & \\
\hline$q$ & Heat transfer rate & $\mathrm{W}$ & $\mathrm{HS}$ & Heat Sink & \\
\hline $\mathrm{t}$ & Thickness & $\mathrm{m}$ & $\mathrm{CH}$ & Channel & \\
\hline
\end{tabular}

\section{NTRODUCTION}

Micro-channels heat sinks are used in the cooling of electronic devices since it can extract a large quantity of heat for a small region, Because of its ability to absorb heat generated in devices. Cooling fluids used in micro-channels heat sinks are establish an important part of cooling applications, and physical properties for these fluids used are affect the cooling capacity. Using MEPCM suspensions is more activate due to their abilities of enhancement performance of thermal energy storage and convection heat transfer. This heat transfers improvement due to latent heat absorption through the melting process by the PCM 


\section{AL-QADISIYAH JOURNAL FOR ENGINEERING SCIENCES}

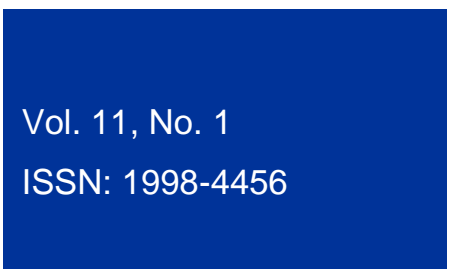

suspended of MEPCM particles. There are many researchers in literature who studied the performance of micro-channels heat sink and the use of micro-encapsulated phase change materials suspensions.

RAMI S. et al. (2008)[1] Numerically investigated the use of microencapsulated phase change materials suspension in heat transfer of fluid to improve the presentation of micro-channel heat sink. They used three dimensional geometric model to invent the flow and heat transfer in the suspension. The microencapsulated contains of phase change materials (RT44) and which have a specified variety of temperature of solidify and melt. The heat flux applied on the base is (100-500) $\mathrm{W} / \mathrm{cm}^{2}$ and the dimensions of the micro-channel heat sink are $5.1 \mathrm{~mm}$ width, $1.5 \mathrm{~mm}$ height and length of $10 \mathrm{~mm}$. The micro-channel heat sink consists of 25 equally space of rectangular channels each with $100 \mu \mathrm{m}$ width, $500 \mu \mathrm{m}$ depth and $10 \mathrm{~mm}$ length. Wall thickness for the channels separated by a $100 \mu \mathrm{m}$ and made from aluminum for the same material of heat sink. Their results indicated that, due to using these microencapsulated the specific heat capacity, thermal conductivity and fluid effective are enhanced due to latent heat effect and micro-mixing respectively. MUSHTAQ I. HASAN (2011)[2] Numerically investigated the micro channel heat exchanger with microencapsulated phase change material suspension in counter flow. The MEPCM suspension contains of microcapsules constructed from the shell material is poly methyl methacrylate and $n$-octadecane as a phase change material. The concentration of these capsules suspended in water are (0-20)\%. He found that, using of MEPCM suspensions led to increase the pressure drop and modify thermal presentation of a counter flow micro channel heat exchanger with increasing its effectiveness. SAMIRA M. and SAMAD S.(2014)[3] Numerically investigated the latent heat of thermal energy storage methods. They studied the influence MEPCM slurry on temperature of the hot and cold fluids. They used different volumes fractions of MEPCM slurry. thermal boundary condition applied on the bottom wall of a heat sink is a constant heat flux of $100 \mathrm{~W} / \mathrm{cm}^{2}$. Their results indicated that, by using MEPCM at $25 \%$ volume fraction indications to the enhancement in fluid temperature that is, the rate of rise temperature for cold fluid decreases to $9 \%$ and the rate of reduction temperature for hot fluid increases up to $23.5 \%$, related to using water only in the microelectronic mechanical system. SAMAD S. and SAMIRA M. (2015)[4] Numerically investigated the enhancement thermal performance of a micro-channel heat sink by using nanoencapsulated phase change material (NEPCM) suspension as a cooling fluid replace of pure fluid. A three dimensional model of a rectangular channel by using NEPCM suspended in water was developed. The PCM is n-octadecane (NEPCM core) and Polystyrene (NEPCM wall). The inlet temperature is equal to $300 \mathrm{~K}$, inlet velocity is $1 \mathrm{~m} / \mathrm{s}$ and the melting range used for PCM is $300-500 \mathrm{~K}$. They analyzed the NEPCM is suspended in water in a concentration of (020) \%. Their results presented a significant decrease in wall temperature of heat sink and the mean temperature of fluid along the channel below a definite condition for the heat flux amounts that depends on the inlet velocity and volume fraction of the NEPCM suspension. MUSHTAQ I. HASAN (2017)[5] Numerically investigated for improving the cooling performance of electrical distribution transformer using transformer oil - based MEPCM suspension. The volume concentration as a coolant fluid in place of pure transformer oil is $(5-25) \%$. The phase change material used in his study is paraffin wax $\left(C_{20} H_{42}\right)$ to manufacture the suspension. He found that, when using of MEPCM suspension in place of pure transformer oil lead to enhance the cooling performance of MEPCM suspension and transformer by decreasing its temperature. XU HAN et al. (2017)[6] Experimentally studied a new microencapsulated phase change material. In their study they used organic phase change material (n-octadecane) as a core and poly methyl methacrylate as a shell. Their results indicated that the range of the mean diameter is (2-3) $\mu \mathrm{m}$, by a uniform distribution size, and the phase change temperature is $26.2 \mathrm{C}^{\circ}$ and enthalpy of microencapsulated phase change material is $139.68 \mathrm{~J} / \mathrm{g}$. Their results showed that at (2 to 3 ) $\mathrm{mm}$ thick covering containing of microencapsulated phase change material the amplitude temperature decreased by (5-6) $C^{\circ}$ and power monitoring for the period of the higher temperature indicated that in one day the time startup of air condition expectedly decreased, thus saving electric consumptions about $26 \%$. NATHAN S. et al. (2017)[7] Experimentally investigated and provided a technique of heat transfer development using microencapsulated phase change material suspension. They tested two types of microcapsules PCM 


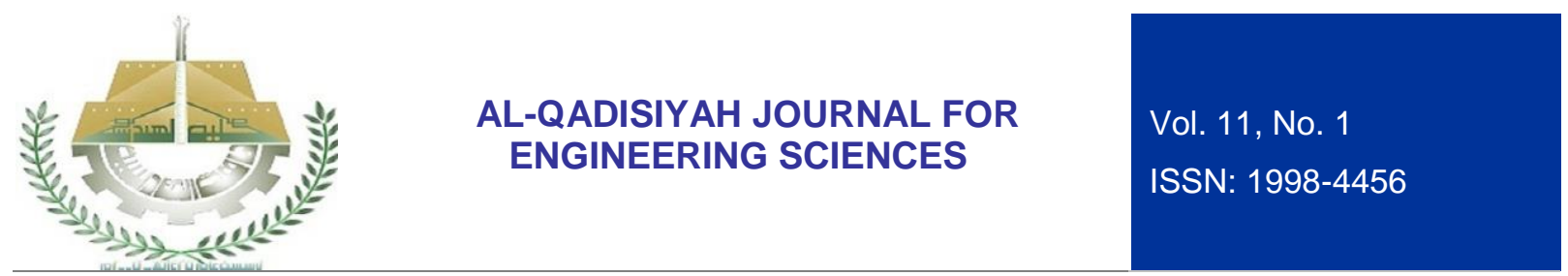

(metal coated and non-metal coated) were tested during a short tube micro channel heat exchanger by different fluid flow rates and different concentrations (5 and $10 \mathrm{wt}$ \%)PCM. They found that $h_{f}$ is increased by 3.5 times compare with pure water when the ratio $10 \%$ of non-metal covered MPCM slurry which used. The metal covered MPCM slurry presented a further $10 \%$ increasing in $h_{f}$ related to the non-metal covered at same Reynolds number and MPCM concentration. SOMAYEH L. et al. (2017)[8] Experimentally investigated the effect of shell flexibility on the encapsulation efficiency and thermal performance of the microcapsules. The series of microcapsules, containing n-hexadecane (HD) as the core, and polymethyl methacrylate (PMMA) and poly(butyl acrylate-co-methyl methacrylate) (poly(BA-co-MMA)) as the shells were prepared through suspension polymerization. Their results showed that, Thermal properties of the microcapsules were estimated by differential scanning calorimetry (DSC) and dynamic mechanical thermal analysis (DMTA) was performed to evaluate the rigidity of shells with two distinct $\mathrm{T} g S$ for poly(BA-co-MMA).

\section{1-ENCAPSULATION OF PCMS:}

The development of using encapsulation increases the heat transfer coefficient and heat transfer area of the system. It is also considerate in forming a protecting and obstruction the PCM from the controlling the volume changes and outside surrounding of the PCM. Encapsulated PCMs are collected of shell is inorganic material or polymer and PCMs as a core to obtain the required shape of encapsulated also prevents PCM through phase change process from leakage. The encapsulated PCMs dependent on the size, are classified in to Micro PCMs, Macro PCMs and Nano PCMs. The size of Macro PCMs is larger than $1 \mathrm{~mm}$, the size of Nano PCMs is smaller than $1 \mu \mathrm{m}$ and Micro PCMs usually varies from $1 \mu \mathrm{m}$ to $1 \mathrm{~mm}$. Due to the influence like reduction of the PCMs reactivity through outside surrounding, increase in area of the heat transfer and establishment for the resist changes in size to core material of the PCM, such as the phase change happens they have involved significant importance in the ranges of energy storage similar solar energy storage application, thermo-regulated foams and fibers, energy-saving of building materials, etc. [11].

\section{2- PROBLEM DESCRIPTION:}

The physical model studied of the problem is shown in Fig.1.a which represents the micro channel heat sink (MCHE) which consists of rectangular channel and the flow is consider single phase. The length of the micro channel heat sink is $20 \mathrm{~mm}$, width $200 \mu \mathrm{m}$ and height $100 \mu \mathrm{m}$. Flow in this model is developing and conjugating heat transfer where the 3D governing equations used for solving this model are continuity, momentum and energy requisite be solved of the two solid and fluid wall instantaneously. Due to the thermal symmetry and geometrical between rows of micro channel's, a heat sink unit consists of one channel shown in Fig.1.b will be used for solving and representing the complete heat sink.

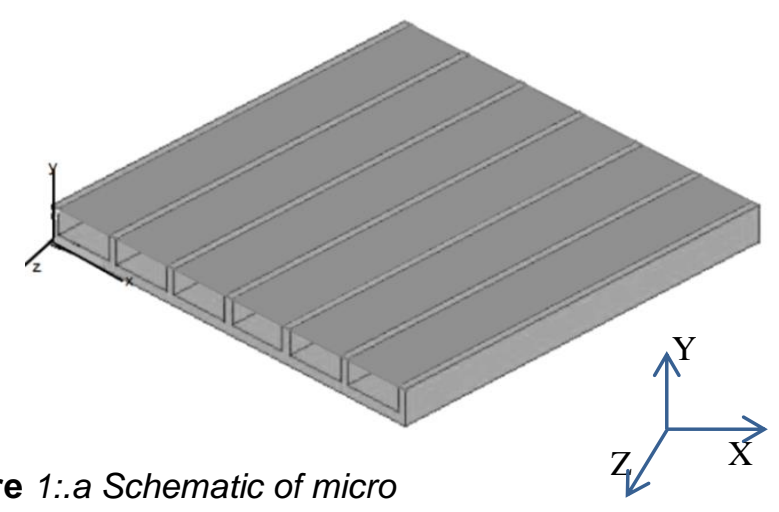

Figure 1::a Schematic of micro channel heat sink

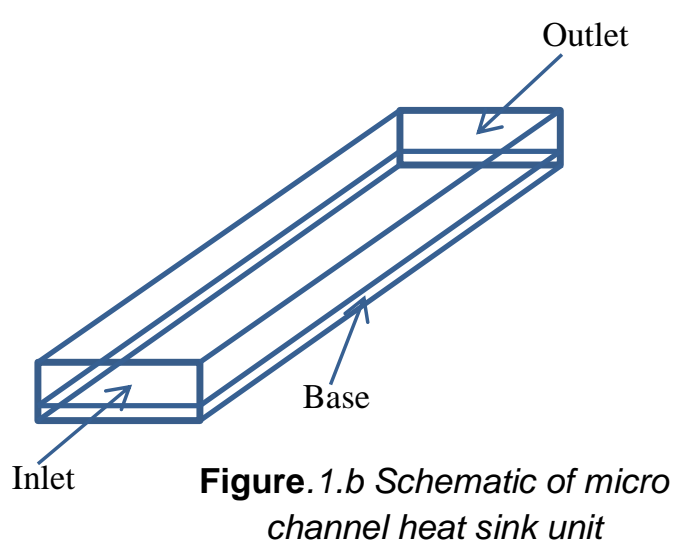

channel heat sink unit 


\section{3- MATHEMATICAL MODEL:}

\section{3-1- Governing equations:}

The governing equations which are represented by continuity, momentum and energy used for pure fluid and suspension are the same. The governing equations can be written as following $[2,9,10,11]$ :

The continuity equation:

$$
\frac{\partial u}{\partial x}+\frac{\partial v}{\partial y}+\frac{\partial w}{\partial z}=0
$$

Momentum equations:

$$
\begin{aligned}
& u \frac{\partial u}{\partial x} v \frac{\partial u}{\partial y}+w \frac{\partial u}{\partial z}=-\frac{1}{\rho} \frac{\partial \rho}{\partial x}+\frac{\mu}{\rho}\left(\frac{\partial^{2} u}{\partial x^{2}}+\frac{\partial^{2} u}{\partial y^{2}}+\frac{\partial^{2} u}{\partial z^{2}}\right) \\
& u \frac{\partial v}{\partial x} v \frac{\partial v}{\partial y}+w \frac{\partial v}{\partial z}=-\frac{1}{\rho} \frac{\partial \rho}{\partial y}+\frac{\mu}{\rho}\left(\frac{\partial^{2} v}{\partial x^{2}}+\frac{\partial^{2} v}{\partial y^{2}}+\frac{\partial^{2} v}{\partial z^{2}}\right) \\
& u \frac{\partial w}{\partial x} v \frac{\partial w}{\partial y}+w \frac{\partial w}{\partial z}=-\frac{1}{\rho} \frac{\partial \rho}{\partial z}+\frac{\mu}{\rho}\left(\frac{\partial^{2} w}{\partial x^{2}}+\frac{\partial^{2} w}{\partial y^{2}}+\frac{\partial^{2} w}{\partial z^{2}}\right)
\end{aligned}
$$

Energy equation:

$$
\rho C p\left(u \frac{\partial H e}{\partial x}+v \frac{\partial H e}{\partial y}+w \frac{\partial H e}{\partial z}\right)=k\left(\frac{\partial^{2} T}{\partial x^{2}}+\frac{\partial^{2} T}{\partial y^{2}}+\frac{\partial^{2} T}{\partial z^{2}}\right)
$$

The enthalpy of the suspension $(\mathrm{He})$ is described by Eq. (6) and calculated from sum quantity of the sensible heat $(\mathrm{SH})$ and the latent heat $(\Delta \mathrm{H})$ of the PCM

$$
\mathrm{H} e=\mathrm{SH}+\Delta \mathrm{H}
$$

The sensible heat is defined by Eq. (7), where $h_{r e f}$. is the reference enthalpy at $T_{r e f}$.

$$
h e=h_{\text {ref. }}+\int_{T_{\text {ref. }}}^{T} C P_{F} \mathrm{dt}
$$

The latent heat $(\Delta \mathrm{H})$ of the slurry is defined by Eq. (8) as a function of the MEPCM mass fraction $(\varphi)$, latent heat of fusion of the PCM (L) and melted mass fraction $(\beta)$. The melted mass fraction $(\beta)$ is defined as the mass ratio of melted PCM to the total mass of PCM in the slurry. The PCM start to melt at $T_{\text {solidus }}$ and completing melting at $T_{\text {liquids }}$ where the liquid fraction can vary from 0 at $T_{\text {solidus }}$ to 1 at $T_{\text {liquids }}$ Eq. (9), which is known as the lever rule, describes the melted mass fraction $(\beta)$.

$$
\Delta \mathrm{H}=\beta \varphi \mathrm{L}
$$

where:

$$
\begin{array}{ll}
\beta=0 & \text { if } T_{f}<T_{\text {solidus }} \\
\beta=0 \quad & \text { if } T_{f}>T_{\text {liquids }} \\
& \beta=\frac{T_{f-T_{\text {solidus }}}}{T_{f}-T_{\text {liquids }}} \quad \text { if } T_{\text {solidus }}<T_{f}<T_{\text {liquids }}
\end{array}
$$




\section{3-2- Model boundary conditions}

The boundary conditions used to close the mathematical model are:

1- No slip at wall $u=v=w=0$.

2- Constant heat flux at the bottom wall, $Q=$ Qin.

3- Insulated top wall of micro channel heat sink unit.

4- Symmetry B.C at the right and left sides of micro channel heat sink unit.

5- Inlet and outlet uniform $\mathrm{V}=V_{i}, \mathrm{~T}=T_{i}$.

6- Fully developed flow at the end of channel (stagnation pressure $=0$ ).

7- No slip conjugate heat transfer between interface fluid - solid.

\section{4- SPESIFICATION OF MICROCAPSULES:}

MEPCM particles consist of polymers surrounding a core of PCM. The polymer wall is flexible sufficiently to arrange for accommodations volume changes that complemented by solid/liquid phase change. Fig.2 shows a single MEPCM particle which is consists of two parts: the outer polymer is shell material and the inner phase change material and moving interface between solid and liquid PCM. The inspected MEPCM particles which have average diameter is $5 \mu \mathrm{m}$ has been investigation. Two shell materials are studied (poly-methyl-methacrylate (PMMA), poly-alpha-olefin (PAO)) with the core materials are (n-octadecane and RT44). The core material (PCM) is about $70 \%$ by volume in a single MEPCM particle. There are more important factors which are governed by chosen of the suspending fluid, its compatibility with PCMs and the microcapsule wall therefore the physical properties of the wall material and PCMs are different. The properties of the MEPCM must be calculated from the properties of the different components. The mass and energy balance correspondingly can be used to calculated density and specific heat of the microcapsules.

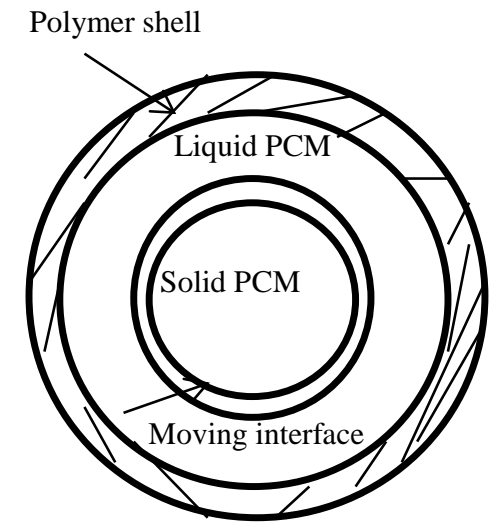

Figure 2: sketch of single MEPCM particle during

$$
\rho_{P C M}=\frac{10}{7}\left(\frac{d_{c}}{d_{P C M}}\right)^{3} \rho_{C}
$$




\section{AL-QADISIYAH JOURNAL FOR ENGINEERING SCIENCES}

Vol. 11 , No. 1

ISSN: $1998-4456$

$$
C_{P P C M}=\frac{(7 C p c+3 C p w a l l) \rho_{c} \rho_{w a l l}}{(3 \rho c+7 \rho w a l l) \rho_{P C M}}
$$

The calculation of thermal conductivity of the microcapsules by using compound sphere approach is given by:

$$
\frac{1}{K_{P C M} d_{P C M}}=\frac{1}{K_{C} d_{c}}+\frac{d_{P C M}-d_{c}}{K_{w a l l} d_{P C M} d_{c}}
$$

\section{5- PROPERTIES OF SUSPENSION:}

The properties of the suspension are a mixture of the properties of the microcapsules and suspending fluid. The density and specific heat are calculated by using mass and energy balance $[2,5,11,12]$.

$$
\begin{gathered}
\rho_{f}=C \rho_{P C M}+(1-C) \rho_{W} \\
C_{P F}=\varphi C_{P P C M}+(1-\varphi) C_{p w}
\end{gathered}
$$

Where $\varphi$ is the mass fraction which can be calculated by:

$$
\varphi=\frac{C \rho_{P C M}}{\left(\rho_{w}+c\left(\rho_{P C M}-\rho_{w}\right)\right)}=\frac{C \rho_{P C M}}{\rho_{f}}
$$

The viscosity of the suspension was calculated from the relation:

$$
\mu_{f}=\mu_{w}\left(1-\mathrm{c}-1.16 C^{2}\right)^{-2.5}
$$

This relation has been presented to be effective for concentration up to $20 \%$ and mean particle diameter of $0.3-400 \mu \mathrm{m}$ and ratio of channel-to particle diameter of $20-100$.

To calculate the thermal conductivity of suspension following relationship was used:

$$
\mathrm{K}_{\mathrm{f}}=\frac{2 k_{w}+k_{P C M}+2 C\left(K_{p c m}-k_{w}\right)}{2+\frac{K_{P C M}}{k_{w}}-C\left(\frac{k_{P C M}}{K_{w}}-1\right)}
$$

To calculate the performance of heat sink is ratio of heat transfer to the pumping power we use:

$$
\eta=\frac{q}{p \cdot p}
$$

Where P.P is the pumping power:

$$
p \cdot p=\Delta p \cdot m \cdot(19)
$$

pressure drop is equal to:

$$
\Delta \mathrm{p}=p_{\text {out }}-p_{\text {in }}
$$

Flow rate is equal to:

$$
m \cdot=\mathrm{A} \cdot \mathrm{V}
$$




\section{AL-QADISIYAH JOURNAL FOR ENGINEERING SCIENCES}

Vol. 11 , No. 1

ISSN: 1998-4456

The MEPCM suspension concentration used in this paper were (2\%, $5 \%, 10 \%, 15 \%$ and $20 \%)$. Table1 shows the thermo-physical properties of studied materials [11,12].

Table 1 physical properties of suspension components [11,12]

\begin{tabular}{|l|l|l|l|c|}
\hline Material & $\rho(\mathrm{kg} / \mathrm{m} 3)$ & $C p(\mathrm{~J} / \mathrm{kg} \mathrm{K})$ & $\mathrm{K}(\mathrm{W} / \mathrm{m} \mathrm{K})$ & $\mu(\mathrm{kg} / \mathrm{m} \mathrm{s})$ \\
\hline Pure Water & 981.3 & 4189 & 0.643 & 0.000598 \\
Ethylene glycol & 1111.4 & 2415 & 0.254 & 0.0157 \\
Transformer oil & 870 & 2000 & 0.109 & 0.0124 \\
RT44 (Rubitherm) (PCM) & 771 & 2000 & 0.2 & - \\
N-octadecane (PCM) & Solid $=850$ & 2222 & 0.358 & - \\
& Liquid $=780$ & & & - \\
PMMA (MEPCM wall) & 1190 & 1470 & 0.21 & - \\
PAO (MEPCM wall) & 783 & 2242 & 0.143 & \\
\hline
\end{tabular}

\section{6- NUMERICAL SOLUTION:}

A finite volume method (FVM) is used to find solutions of governing equations and boundary conditions of the above system numerically. Computing fluid dynamics (CFD) has been model to solve the numerical model. SIMPLE algorithm is used to solve the problem of coupling to computing the flow variables by solving the continuity, momentum, energy equations. The mesh is chosen for solving the system by recognizing grid size since a mesh refinement has been made to find suitable mesh size that give a high accurate solution. Fig. 3 shows the model flow chart for numerical solutions by using CFD. Table 2 shows the different meshes selected and from this table it can be seen that, the solution becomes independent of mesh size after the fourth mesh, therefore the fourth mesh will be used for all next solutions.

The convergence conditions used to control the numerical solution is $10^{-6}$ for both energy and momentum equations.

Table 2 Grid independent study

\begin{tabular}{|c|c|}
\hline Mesh size & Outlet temperature (K) \\
\hline Mesh1 (interval size $=0.0005$ ) & 314.4 \\
\hline Mesh2 (interval size $=0.0004$ ) & 314.5 \\
\hline Mesh3 (interval size $=0.0003$ ) & 314.78 \\
\hline Mesh4 (interval size $=0.0002$ ) & 314.17 \\
\hline Mesh5 (interval size $=0.00015)$ & 314.02 \\
\hline Mesh6 (interval size $=0.0001$ ) & 314 \\
\hline
\end{tabular}




\section{AL-QADISIYAH JOURNAL FOR ENGINEERING SCIENCES}

Vol. 11 , No. 1

ISSN: $1998-4456$

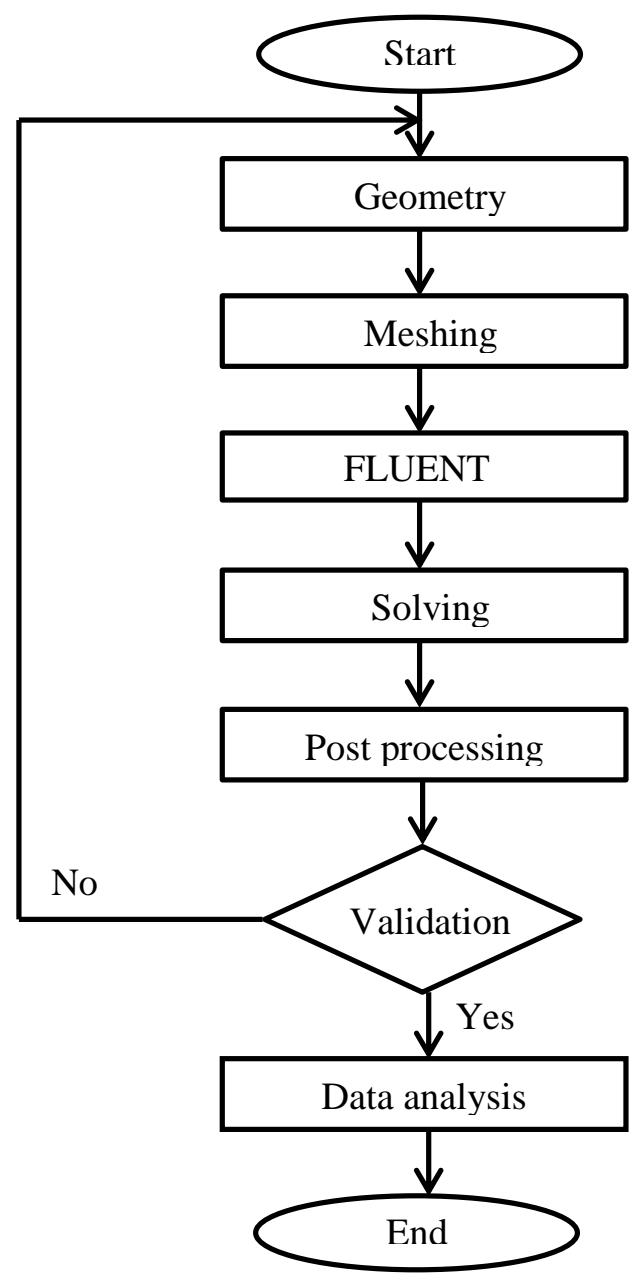

Figure 3:model flowchart

\section{7- RUSULTS AND DISCUSSIONS:}

\section{7-1- Validation:}

To check the validity of used numerical model, this model is validated with numerical model presented in [1]. The numerical model presented in [1] is micro-channel heat have vertical height $1.5 \mathrm{~mm}$, length $10 \mathrm{~mm}$ and width $5.1 \mathrm{~mm}$. The MEPCM water slurry is analyzed with volume fraction of $0 \%$ (pure water), $5 \%, 10 \%, 15 \%$, $20 \%$ and $25 \%$. For this study the temperature was measured in the base of heat sink, at the boundary conditions applied on this model at different inlet temperature of $25 \mathrm{C}^{\circ}$, inlet velocity $1 \mathrm{~m} / \mathrm{s}$ and constant heat flux of $100 \mathrm{~W} / \mathrm{cm}^{2}$ subjected on the bottom wall of the model for the different models of designs.

Fig.4 shows the comparison between the numerical results of [1] and results of present model for the temperature along the bottom wall of heat sink. It can be noted from this figure that the agreement between results is acceptable where the maximum error is $0.96 \%$. 


\section{AL-QADISIYAH JOURNAL FOR ENGINEERING SCIENCES}

Vol. 11, No. 1

ISSN: $1998-4456$

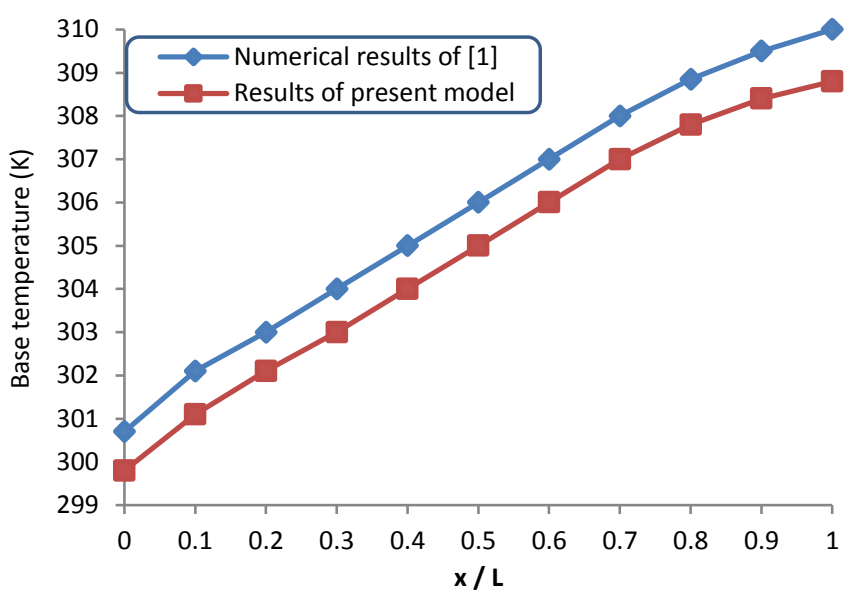

Fig.4 Variation of base temperature along microchannel heat sink as comparison between result of [1] of present model for pure water

\section{7-2- Results:}

In this study, a 3-D micro-channel heat sink with the rectangular channel and MEPCM suspension is numerically investigated. Computing fluid dynamics (CFD) has been code to solve the numerical code. Firstly, the model is solved with pure water, secondary the model is solved with Ethyleneglycol and last the model is solved with pure oil as a cooling fluids with constant properties selected according to the ambient temperature, then the solution is repeated with using MEPCM suspension with different concentrations as a cooling medium instead of pure fluids. Different types of MEPCM core and wall have been simulated to find out the best case which gives higher performance and cooling of heat sink.

Figures $(5 \mathrm{a}$ and $5 \mathrm{~b})$ indicate the contours for temperature at cross sectional plan at $\mathrm{z}=0.002 \mathrm{~m}$ and top longitudinal plan at $\mathrm{y}=0.00015 \mathrm{~m}$ for pure water (base case). From figure $4 . \mathrm{a}$ it can be seen that, the temperature is decreased from the solid walls of heat sink toward the surface the channel, due to absorption of heat by pure water as a results of heat transfer process and transferring the heat to the environment by convection and radiation. For figure $4 . \mathrm{b}$ it can be noted that, the temperature of water is increased along flow direction due to heat transfer from lower wall with constant heat flux.

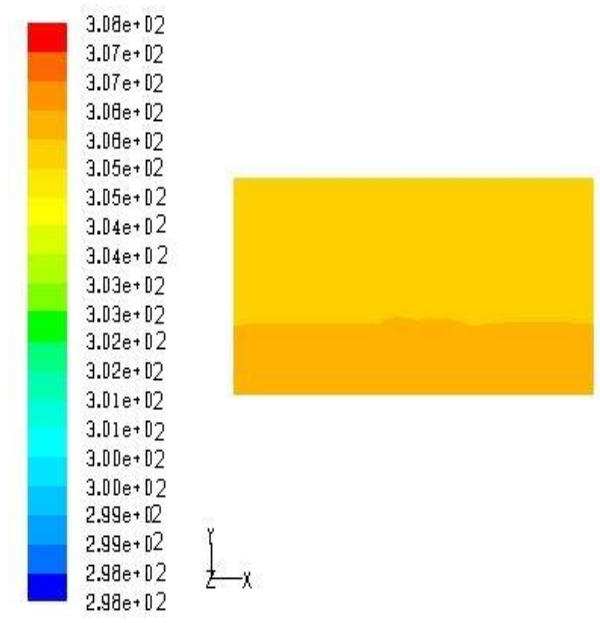

Figure 5:a Cross sectional contour of static temperature for heat sink with pure water at $\mathrm{T}=25 \mathrm{C}^{\circ}$ 


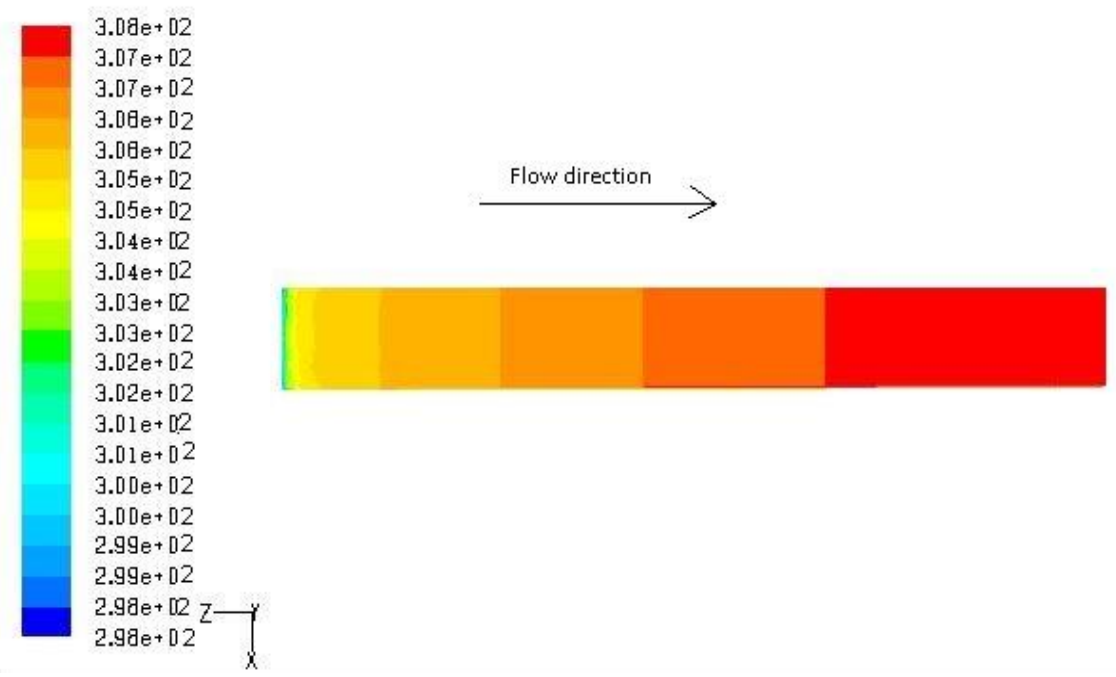

Figure 5:b Longitudinal contour of static temperature for heat sink with pure water at $\mathrm{T}=25 \mathrm{C}^{\circ}$

Fig.6 illustrated the variation of base temperature with ambient temperature for the micro channel heat sink unit filled with pure water (base case) at concentration $0 \%$ and MEPCM suspension for different concentration at $2 \%, 5 \%, 10 \%, 15 \%$ and $20 \%$. From this figure it can be seen that, the base temperature increased with increasing the ambient temperature for all materials used due to decreased in temperature difference and as results decreased in amount of the heat can be transferred from heat sink. When increasing concentration of MEPCM suspension decreased base temperature therefore base temperature at concentration $20 \%$ gives a lower temperature compare with other concentration of MEPCM suspension. From this figure it can be noted that, the temperature of heat sink decreased by using MEPCM suspension compared with pure water (base case) because the MEPCM can absorbs added heat as a latent heat due to melting process. For this figure used (RT44) MEPCM core with PMMA (MEPCM wall) for all materials above the core material (PCM) in a single MEPCM particle is about $70 \%$ by volume.

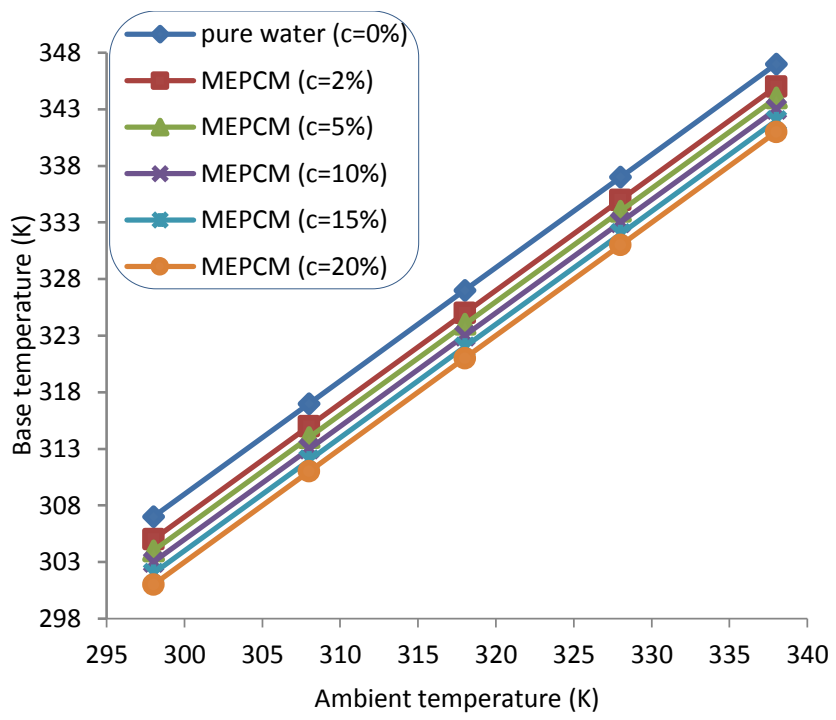

Figure 6: Variation of base temperature with ambient temperature of pure water and RT44 with PMMA suspension at different 


\section{AL-QADISIYAH JOURNAL FOR ENGINEERING SCIENCES}

Vol. 11 , No. 1

ISSN: $1998-4456$

Fig. 7 expresses the variation of temperature reduction with ambient temperature for micro channel heat sink unit when filled with pure water (base case) at concentration $0 \%$ and MEPCM suspension for different concentration at $2 \%, 5 \%, 10 \%, 15 \%$ and $20 \%$. From this figure it can be distinguished prominently that, the temperature reduction decreased with increasing the ambient temperature due to decreased in temperature difference and as results decreased in amount of the heat can be transferred from heat sink according to the relationship $T R=\frac{T_{\text {with out } P C M}-T_{\text {with } P C M}}{T_{\text {with out } P C M}} * 100 \%$. It is noticeable that from this figure, the temperature reduction of heat sink for concentration of MEPCM suspension at $20 \%$ of the MEPCM core (RT44) with PMMA (MEPCM wall) gives high temperature reduction compared with other concentration due to properties of PCM and MEPCM wall.

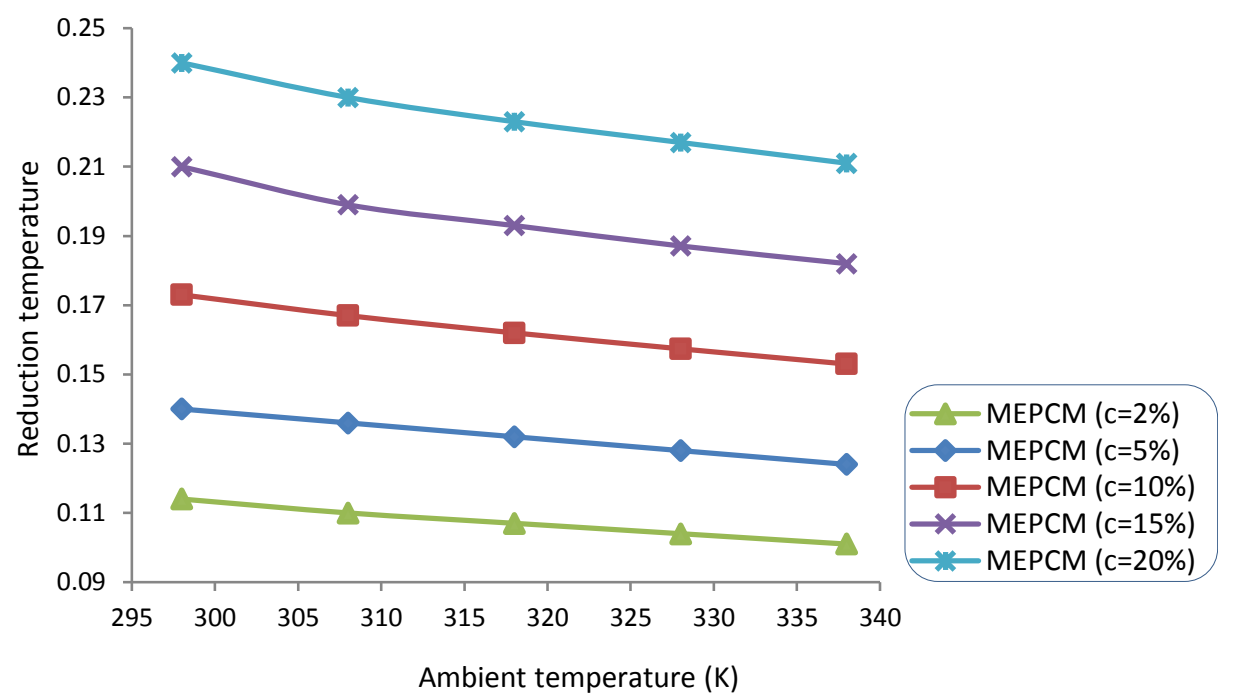

Figure 7:Variation of temperature reduction with ambient temperature for pure water and RT44 with PMMA of suspension at different concentrations

Fig. $(8,9,10$ and 11) show the variation of base temperature with heat flux for the micro channel of heat sink unit when filled with MEPCM suspension at a concentration $2 \%$. These figures reveal that, the base temperature increased with increasing the heat flux values applied on the base of heat sink and MEPCM suspension at $2 \%$ for pure water gives lower base temperature compare with ethyleneglycol and pure oil due to decreased in the temperature of MEPCM suspension and other properties compare with temperature of other pure fluids according to the relationship $\mathrm{TR}=\frac{\mathrm{T}_{\text {with out } \mathrm{PCM}}-\mathrm{T}_{\mathrm{with}} \mathrm{PCM}}{\mathrm{T}_{\text {with out } \mathrm{PCM}}} * 100 \%$. For figure 9 its can be observable that, the MEPCM core (RT44) with PAO (MEPCM wall) for pure water gives a lower temperature compare with other figures due to properties of PCM (RT44) lower density, specific heat and thermal conductivity compare with PCM (n-octadecane) has high density, specific heat and thermal conductivity, and the properties of PAO (MEPCM wall) high specific heat, lower density and thermal conductivity compare with PMMA (MEPCM wall) has high density and thermal conductivity. 


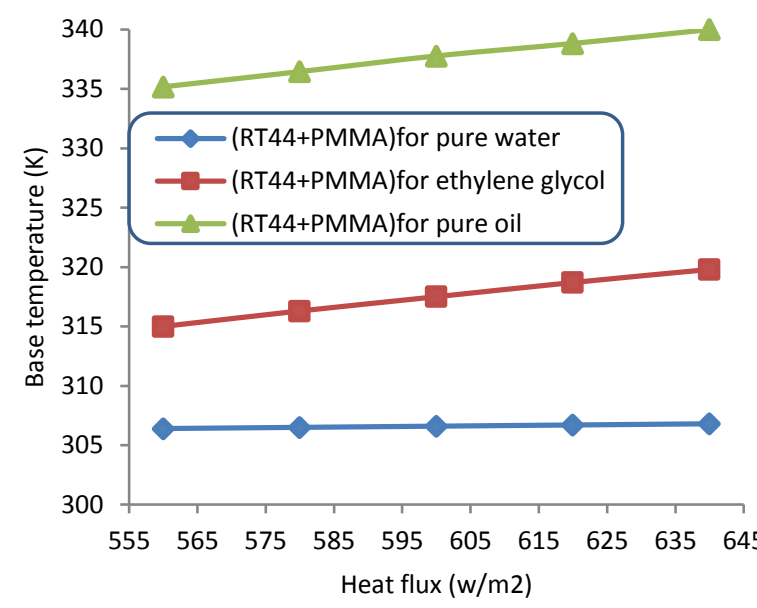

Fig. 8 Variation of base temperature with heat flux for RT44 with PMMA at a concentration $2 \%$

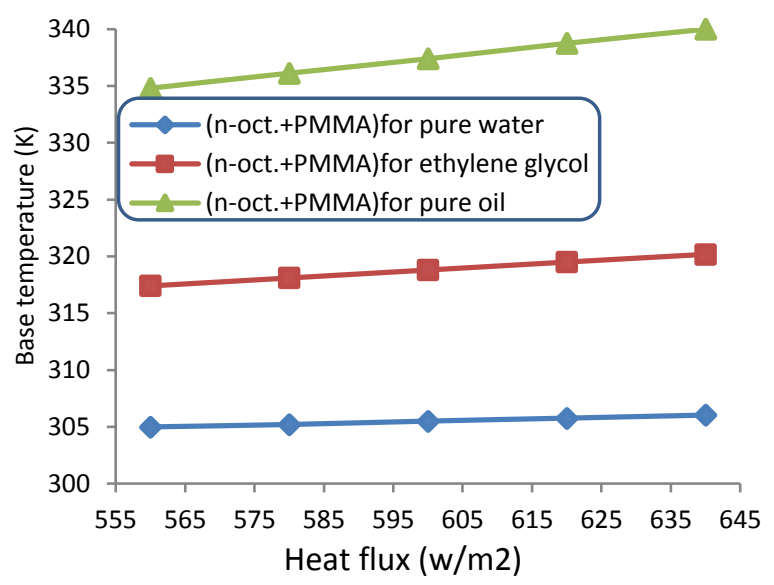

Fig. 10 Variation of base temperature with heat flux for n-octadecane with PMMA at a concentration $2 \%$

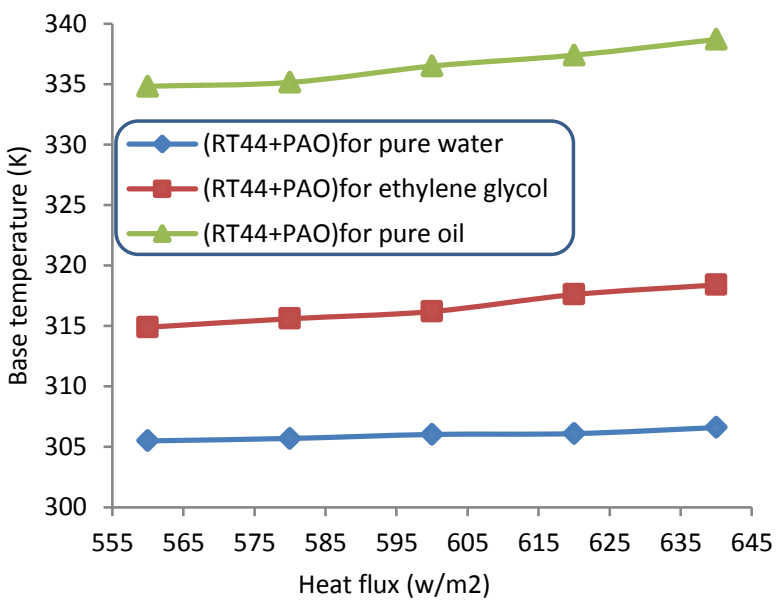

Fig. 9 Variation of base temperature with heat flux for RT44 with PAO at a concentration $2 \%$

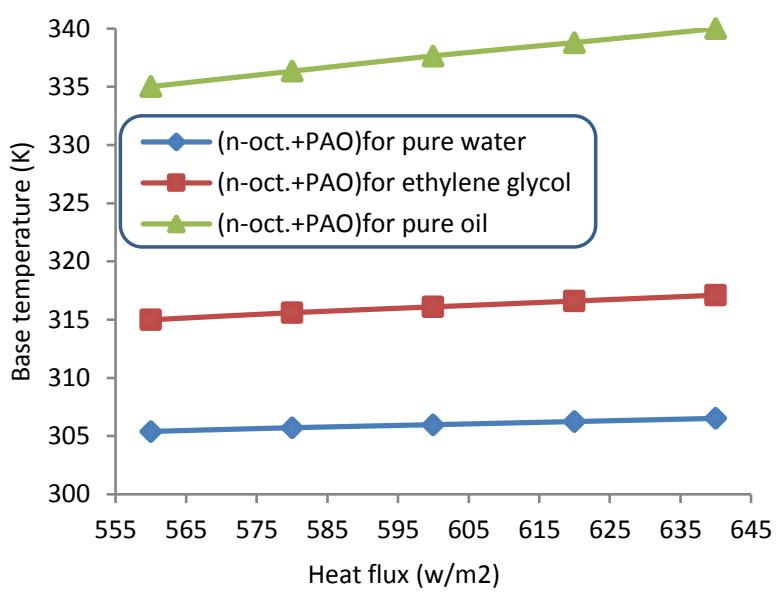

Fig. 11 Variation of base temperature with heat flux for n-octadecane with PAO at a concentration $2 \%$

Figures $(12,13,14$ and 15) display the variation of temperature reduction with heat flux for the micro channel of heat sink unit when filled with MEPCM suspension at concentration at $2 \%$. From these figures it is clear that, the temperature reduction increased with increasing the heat flux values applied on the base of heat sink. Form figure 13, it is obvious that, the MEPCM core (RT44) with PAO (MEPCM wall) for pure water give a lower temperature compare with other figures due to properties of PCM (RT44) lower density, specific heat and thermal conductivity compare with PCM (n-octadecane) has high density, specific heat and thermal 


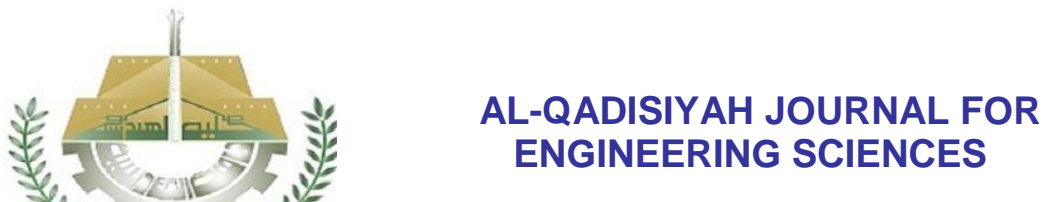

Vol. 11, No. 1

ISSN: $1998-4456$

conductivity, and the properties of PAO (MEPCM wall) high specific heat, lower density and thermal conductivity compare with PMMA (MEPCM wall) has high density and thermal conductivity. The concentration of MEPCM suspension at $2 \%$ gives lower temperature reduction of pure water compare with ethyleneglycol and pure oil according to the relationship $\mathrm{TR}=\frac{\mathrm{T}_{\text {with out }} \text { PCM }-\mathrm{T}_{\text {with }} \mathrm{PCM}}{\mathrm{T}_{\text {with out }} \mathrm{PCM}} * 100 \%$.

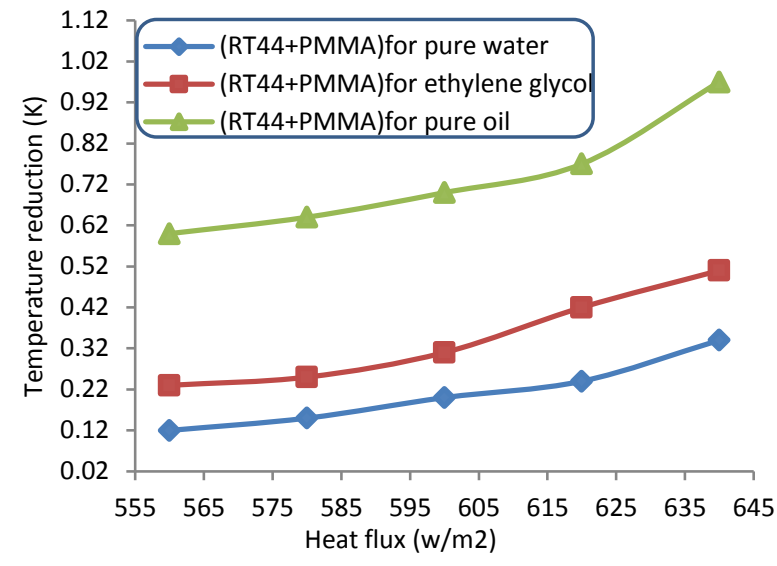

Figure 12: Variation of temperature reduction with heat flux for $\mathrm{RT} 44$ with PMMA at a concentration $2 \%$

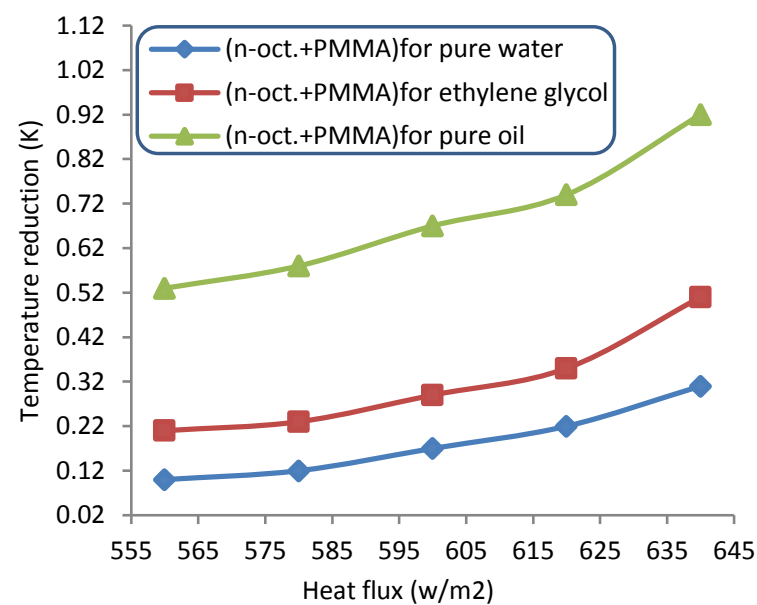

Figure 14:Variation of temperature reduction with heat flux for $n$-octadecane with PMMA at a concentration $2 \%$

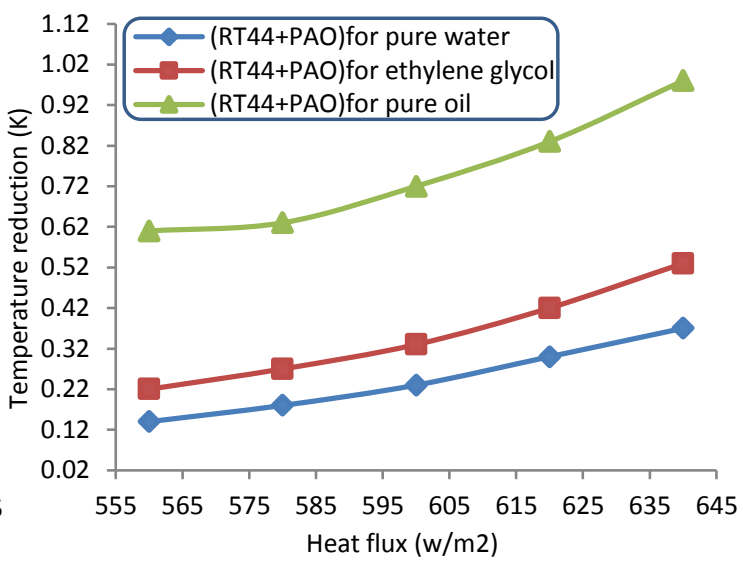

Figure 13: Variation of temperature reduction with heat flux for $R T 44$ with PAO at a concentration $2 \%$

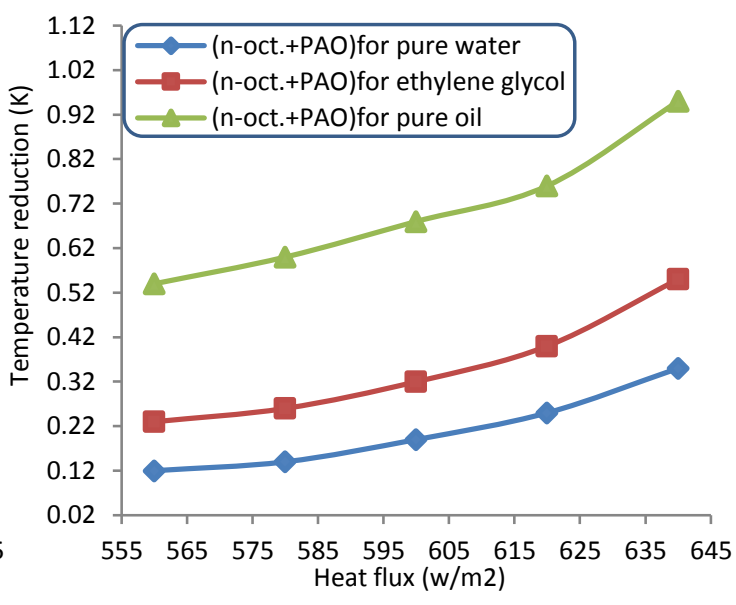

Figure 15:Variation of temperature reduction with heat flux for $n$-octadecane with $P A O$ at a concentration $2 \%$

Fig.16 represents a distribution of Nussle number along micro channel heat sink unit filled with pure water (base case) at concentration $0 \%$ and MEPCM suspension for different concentration at $2 \%, 5 \%, 10 \%$, $15 \%$ and $20 \%$. For this figure used (RT44) MEPCM core with PMMA (MEPCM wall), and for all concentration at a constant inlet temperature, when increasing length of channel the Nussle number decreasing almost on the regular shape due to regular in the temperature distribution along channel and when increased length the temperature increasing since performed that to output temperature higher from input temperature, Nussle number decreasing with decreasing heat transfer coefficient(h). From this figure it can be distinguished that, the MEPCM suspension at concentration $20 \%$ gives higher value of Nussle compare with 


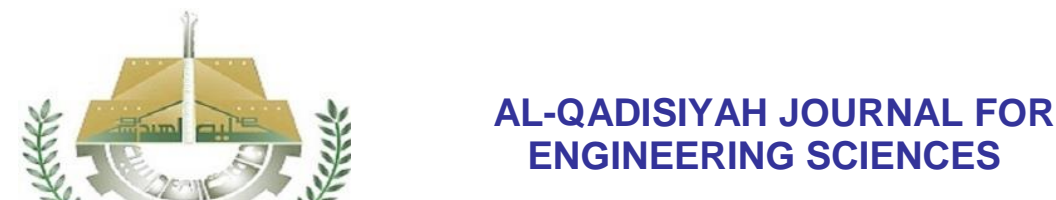

ENGINEERING SCIENCES
Vol. 11, No. 1

ISSN: $1998-4456$

pure water give lower value along the channel due to properties of suspension (temperature, specific heat, thermal conductivity and other properties) decreased when increasing concentration therefore decreasing temperature and give high Nussle number, in pure water inverting happen due to higher properties.

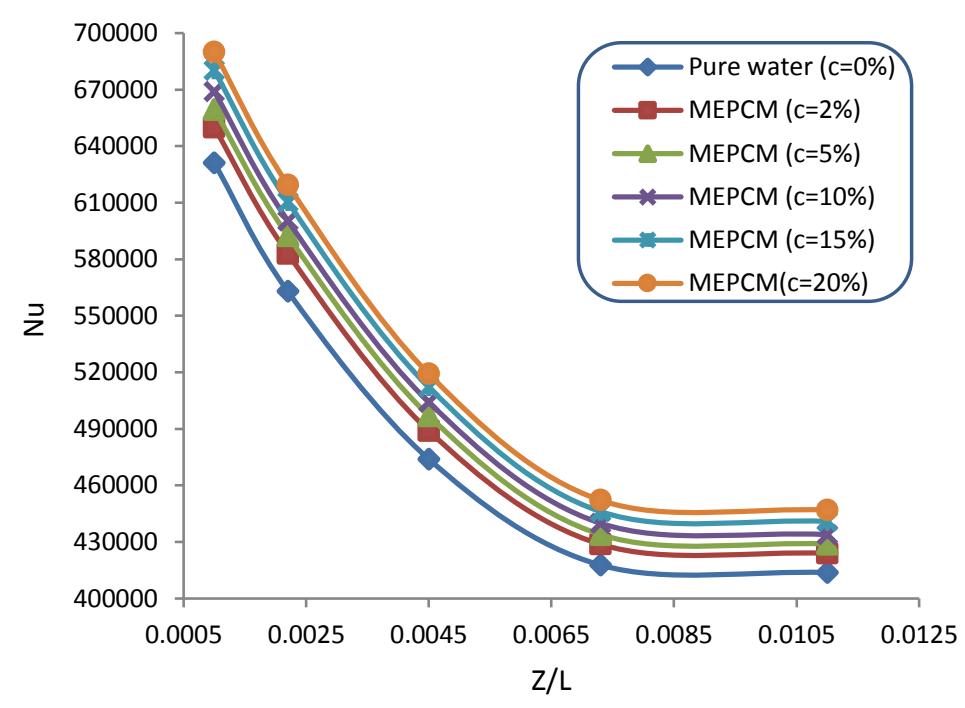

Figure 16:Variation of Nusselt number along channel for pure water and RT44 with PMMA suspension at different concentrations

Fig.17 explains the variation between heat transfer from heat sink and heat flux applied on the base when the heat sink unit filled with pure water at $\mathrm{c}=0 \%$ and MEPCM suspension (RT44 with PMMA) at a concentration $2 \%, 5 \%, 10 \%, 15 \%$ and $20 \%$. From this figure it can be seen that, heat transfer increased with increasing heat flux and pure water give high value of heat transfer due to the increase in heat transfer coefficient $(h)$. when increased concentration, the heat transfer from heat sink decreasing therefore MEPCM suspension at a concentration $20 \%$ gives lower value of heat transfer from the heat sink due to decreasing in the properties of suspension at the concentration $20 \%$.

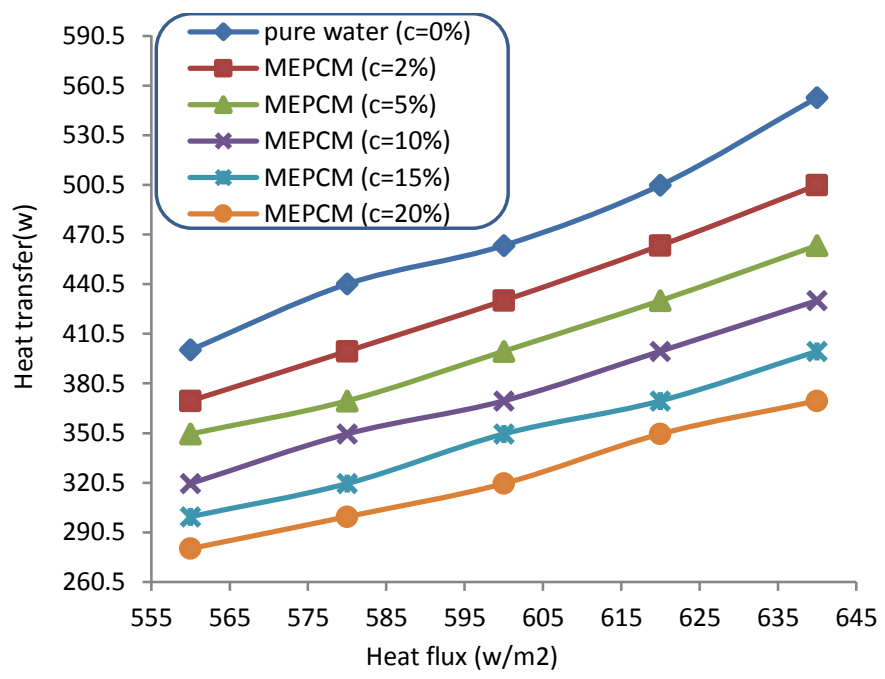

Figure 17: Variation of heat transfer with heat flux for pure water and RT44 with PMMA of suspension at different concentrations 


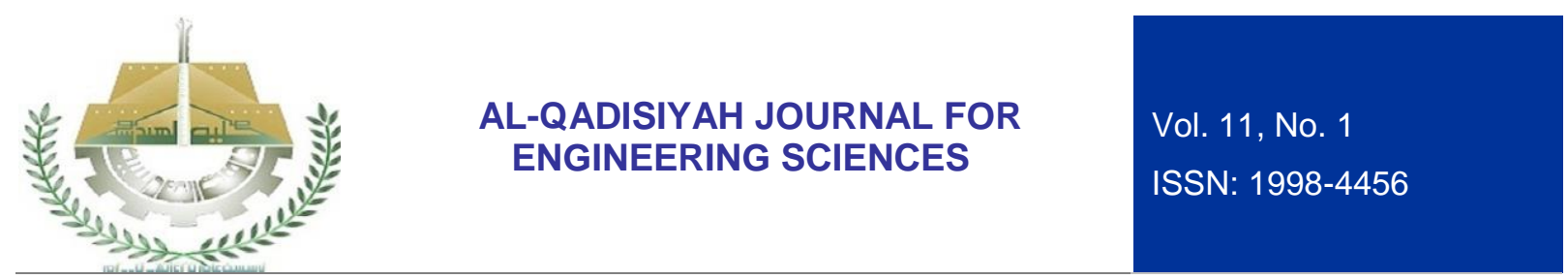

The variation of total pressure drop with heat flux for micro channel heat sink unit when filled with pure water (base case) at concentration $0 \%$ and MEPCM suspension for different concentration at $2 \%, 5 \%, 10 \%$, $15 \%$ and $20 \%$ is shown in Fig. 18 . In this figure (RT44) MEPCM core is used with PMMA (MEPCM wall), and it can be observed that, the total pressure drop increased with increasing concentration of MEPCM suspension compare with pure water for all values of heat flux and MEPCM suspension at concentration $20 \%$ gives high pressure drop compare with other concentration and pure water due to properties of MEPCM suspension.

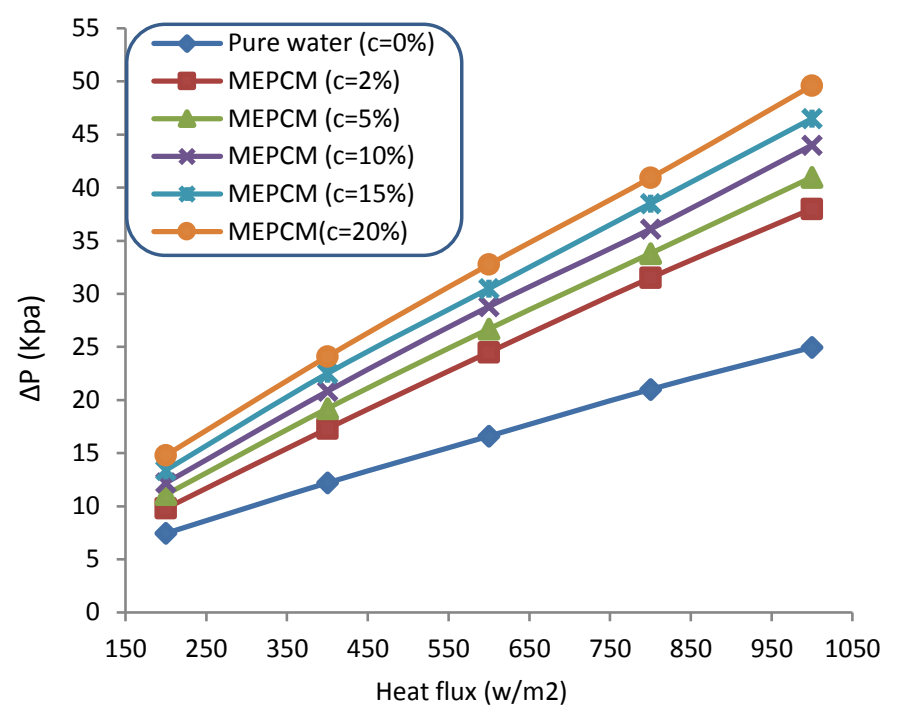

Figure 18:Variation of pressure drop with heat flux for pure water and RT44 with PMMA of suspension at different concentration

Figures $(19,20,21$ and 22) show the variation of performance of the heat sink with the heat flux for the micro channel of heat sink unit when filled with MEPCM suspension at concentration at $2 \%$ and inlet velocity $0.28 \mathrm{~m} / \mathrm{s}$. From these figures it can be perceived that, the performance of MEPCM suspension increased with increasing heat flux for all pure fluid used. From fig.22 (n-octadecane with PMMA) give high performance and MEPCM suspension for pure oil give high performance compared with ethyleneglycol and pure water due to the increased in value of heat transfer from the pure oil and decreasing pressure drop compared with ethyleneglycol and pure water. 


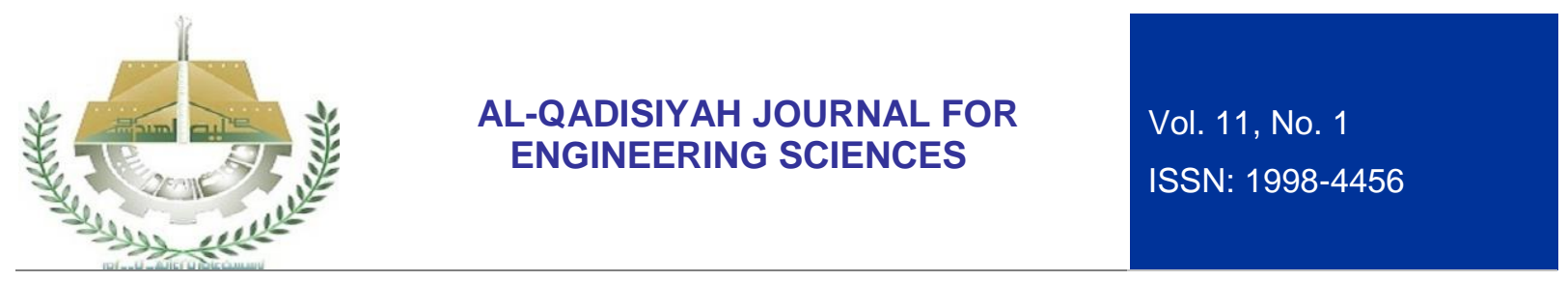

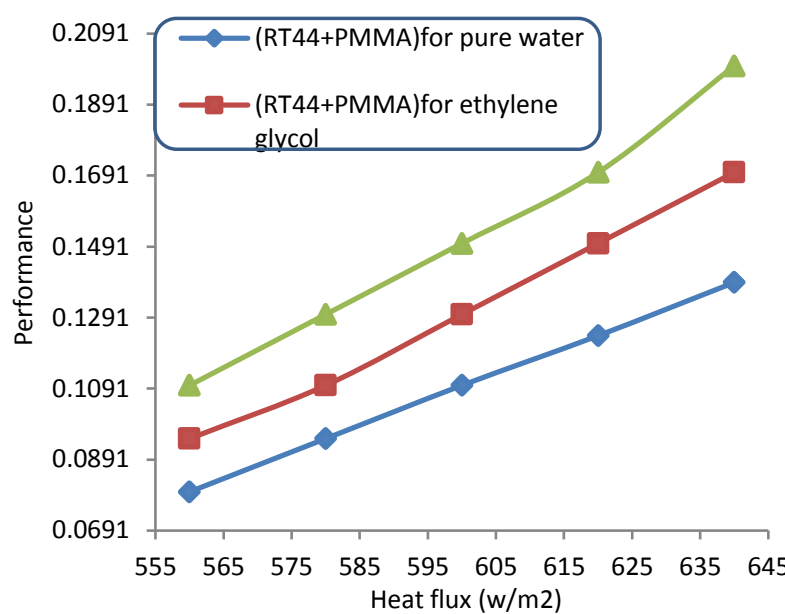

Figure 19: Variation of performance with heat flux for RT44 with PMMA of suspension at a concentration $2 \%$ and $\mathrm{Vi}$

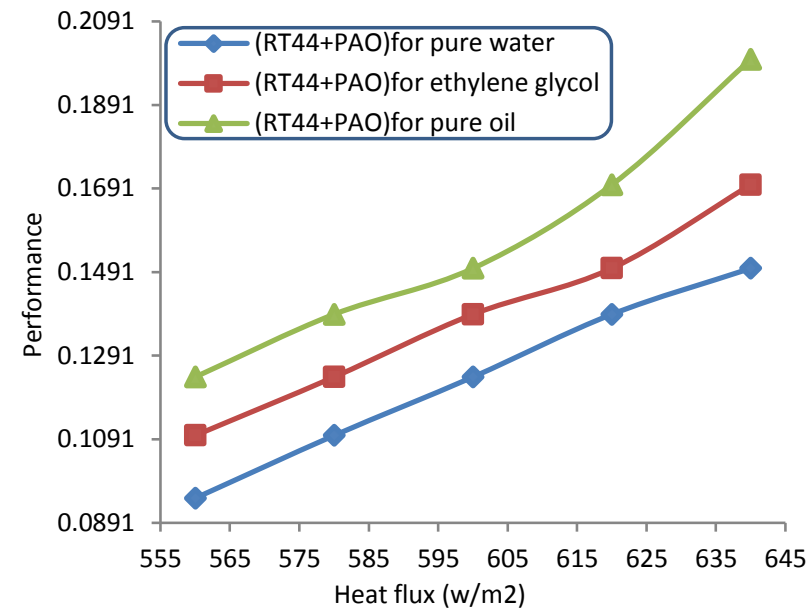

Figure 20: Variation of performance with heat flux for RT44 with PAO of suspension at a concentration $2 \%$ and $\mathrm{Vi}=0.28 \mathrm{~m} / \mathrm{s}$

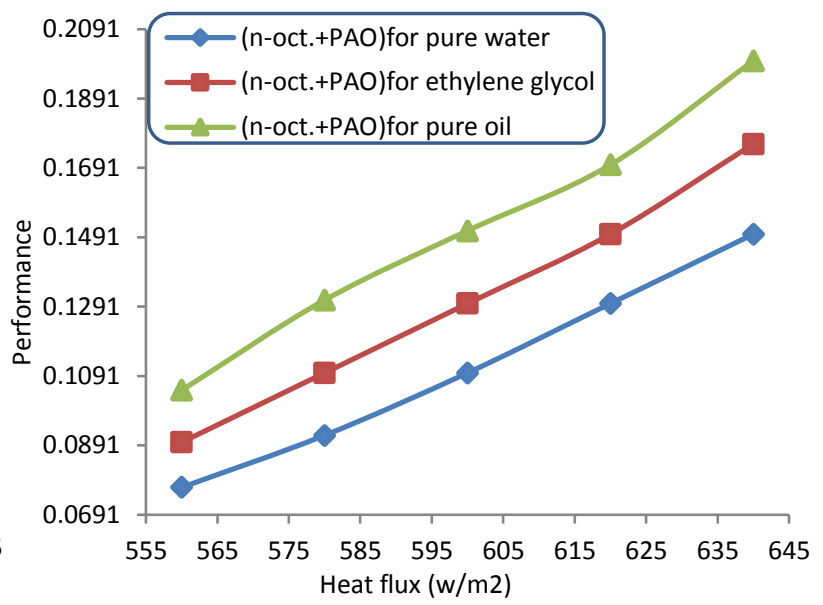

Figure 22: Variation of performance with heat flux for n-octadecane with PAO of suspension at a concentration $2 \%$ and $\mathrm{Vi}=0.28 \mathrm{~m} / \mathrm{s}$

\section{7-3- Conclusion:}

In this paper using of the MEPCM suspension as a cooling fluid instead of pure water, Ethylene glycol and pure oil in micro-channel heat sink for cooling of the electronic divides and modify its cooling performance. From the obtained results the following conclusions can be made:

1- Using of MEPCM suspension in heat sink led to reduce heat sink temperature compared with using pure water, Ethylene glycol and pure oil. 


\section{AL-QADISIYAH JOURNAL FOR ENGINEERING SCIENCES}

Vol. 11, No. 1

ISSN: $1998-4456$

2- Using this type of suspension n-octadecane (MEPCM core) with PMMA( MEPCM wall) and RT44 (MEPCM core) and PAO (MEPCM wall) led to modify thermal performance of MCHS by increasing pressure drop.

3- Using n-octadecane (MEPCM core) with PMMA( MEPCM wall) and RT44 (MEPCM core) and PAO (MEPCM wall) suspensions as a coolant fluid in micro heat sink instead of pure water, Ethylene glycol and pure oil led to enhance the cooling performance of micro heat sink.

4-Variation of temperature reduction (TR) decreased with increasing ambient temperature and increased with increasing heat flux for cooling medium studied.

5- When using RT44 (MEPCM core) and PAO (MEPCM wall) for suspension give lower temperature reduction (TR) compare with using n-octadecane (MEPCM core) PAO (MEPCM wall) for suspension due to high specific heat, thermal conductivity and lower latent heat of fusion.

6- For different applications in electronic devices used micro channel heat sink for a cooling medium from this calculations of different materials its can be noticed that the n-octadecane (MEPCM core) with PMMA( MEPCM wall) for pure water compared with other types give a lower temperature, while RT44 (MEPCM core) and PAO (MEPCM wall) for pure water gives a lower temperature reduction (TR) and gives high performance for pure oil.

7- The cooling performance of micro heat sink is be $20.91 \%$ with (RT44+PMMA) pure oil, $16.91 \%$ with (RT44+PMMA) for ethyleneglycol and $12.91 \%$ with (RT44+PMMA) for pure water at concentration $2 \%$ and $V_{i}$ $=0.28 \mathrm{~m} / \mathrm{s}$.

\section{REFERENCES:-}

1. Rami S., Mohammed M. Farid and Said Al-Hallaj, "Micro-channel heat sink with slurry of water with micro-encapsulated phase change material: 3D numerical study", Journal of Applied Thermal Engineering, 2008, vol. 29, pg. $445-454$.

2. Mushtaq I. Hasan, " Numerical investigation of counter flow microchannel heat exchanger with MEPCM suspension", Applied Thermal Engineering, 2011, vol. 31, pg. 1068-1075.

3. Samira M. and Samad S., " Thermal Performance of MEMS-Based Heat Exchanger with MicroEncapsulated PCM Slurry", Journal of Power and Energy Engineering, 2014, vol. 2, pg. 15-22.

4. Samad S. and Samira M., "Effect of Using Nano Encapsulated Phase Change Material on Thermal Performance of Micro Heat Sink", Int. J. Nanosci. Nanotechnol., 2015, Vol. 11, No. 1, pg. 33-38.

5- Mushtaq I. Husan, " improving the cooling performance of electrical distribution transformer using transformer oil - based MEPCM suspension", Engineering Science and Technology, an International Journal, 2017, Vol.20, No.2, pg.502-510.

6. Xu H., Yong L., Li Y., Qiwei W., Hua Z., Huiliang L., Guoqing Z. and Lvming X., "Experimental study on effect of microencapsulated phase change coating on indoor temperature response and energy consumption", Advances in Mechanical Engineering, 2017, Vol. 9, No.6, pg.1-8. 
7. Nathan S. Roberts, Refat Al-Shannaq, Jamal K., Shaheen A. Al-Muhtaseb and Mohammed M. Farid, " Efficacy of using slurry of metal-coated microencapsulated PCM for cooling in a micro-channel heat exchanger", Applied Thermal Engineering, 2017, Vol. 112, pg.11-18.

8. Somayeh L., Hassan A., Ali R. Mahdavian and Veronica A., " Thermal and morphological studies on novel PCM microcapsules containing n-hexadecane as the core in a flexible shell", Applied Energy, 2017, Vol. 190, pg. 612-622.

9. Mushtaq I. Hasan, Abdul A. Rageb, Yaghoubi M. , Homayony H., "Influence of channel geometry on the performance of counter flow micro channel heat exchanger", Int. Journal of Thermal Sciences, 2009, Vol. 48, pg.1607-1618.

10. Mushtaq I. Hasan, Hayder M. Hasan and Ghassan A. Abid, "Study of the axial heat conduction in parallel flow microchannel heat exchanger ", Journal of King Saud University - Engineering Sciences, 2014, Vol. 26, pg.122-131.

11. Rao Y., Frank D. and Peter S., "Convective heat transfer characteristics of microencapsulated phase change material suspensions in mini-channels", Heat and Mass Transfer, 2007, vol. 44, pg.175-186.

12. Mushtaq I. Hasan, Abdul A. Rageb, Yaghoubi M. , Homayony H., "Investigation of counter flow micr channel heat exchanger performance with using nanofluid as a coolant", Journal of Electronics Cooling and Thermal Control, Scientific Research, 2012, Vol. 2, pp. 35-43. 